\title{
Review
}

\section{Ionic Liquids: Properties, Application, and Synthesis}

\author{
Ehsan Kianfar ${ }^{1,2^{*}}{ }^{(1)}$, Sajjad Mafi $^{3}$ (]) \\ ${ }^{1}$ Department of Chemical Engineering, Arak Branch, Islamic Azad University, Arak, Iran \\ ${ }^{2}$ Young Researchers and Elite Club, Gachsaran Branch, Islamic Azad University, Gachsaran, Iran \\ ${ }^{3}$ Department of Chemistry, Arak Branch, Islamic Azad University, Arak, Iran \\ E-mail: e-kianfar94@iau-arak.ac.ir, ehsan_kianfar2010@yahoo.com
}

Received: 17 October 2020; Revised: 27 November 2020; Accepted: 3 December 2020

\begin{abstract}
Extensive use of toxic and volatile solvents (Volatile) in the chemical industry leads to serious environmental damage. Therefore, finding a suitable alternative for these solvents, which are environmentally sound and at the same time have the properties of common solvents, is strongly felt in the pharmaceutical and chemical industries. New solvents known as solvents as well as green catalysts include supercritical carbon dioxide and Ionic Liquids. Ionic liquids contain organic compounds that are all composed of ions. Ionic liquids (ILs) are a new category of compounds that have received a lot of attention in recent years. These compounds are used as green solvents in many chemical reactions as well as in the construction of advanced materials. In this review, a general description of ILs and historical background are given; the structure of ILs, cation, anion types and synthesis methods in the related literature are summarized. The main application areas and the basic applications also are discussed in detail.
\end{abstract}

Keywords: ionic liquids, power materials, Ionic salts, hypersensitive fuels, environmental, toxic, volatile

\section{Introduction}

Ionic liquids are compounds that have revolutionized research centers and chemical industries in recent years. ${ }^{1-5}$ These compounds, which are part of green chemicals like solvents, have a very important role in reducing the use of hazardous, toxic, and environmentally harmful. ${ }^{6-9}$ Today, ionic liquids are organic compounds made up of ions that are liquid at $100^{\circ} \mathrm{C}$. One of the reasons that have intensified research on ionic fluids today is that scientists are looking for a viable alternative to volatile solvents in the industry. ${ }^{10-15}$ Organic volatile solvents are the most important source of environmental pollution in the chemical and pharmaceutical. ${ }^{16-19}$ Of course, this does not mean that ionic liquids are all green solvents, even some of them are highly toxic. ${ }^{20-21}$ This new chemical group can reduce the use of hazardous and polluting organic solvents due to their unique characteristics as well as taking part in various new syntheses. ${ }^{22-25}$ ILs are known as salts that are liquid at room temperature in contrast to high-temperature molten salts. ${ }^{26-27}$ Studies $^{28-35}$ pointed out in 1980, that there were only a few patent applications for ILs, in 2000, the number of patent applications increased to 100 , and finally by 2004 , there were more than 800 . This is a clear indication of the high affinity of the academia and industry to the ILs ${ }^{36-48 .}$

Copyright (C2020 Ehsan Kianfar, et al.

DOI: https://doi.org/10.37256/fce. 212021693

This is an open-access article distributed under a CC BY license

(Creative Commons Attribution 4.0 International License)

https://creativecommons.org/licenses/by/4.0/ 


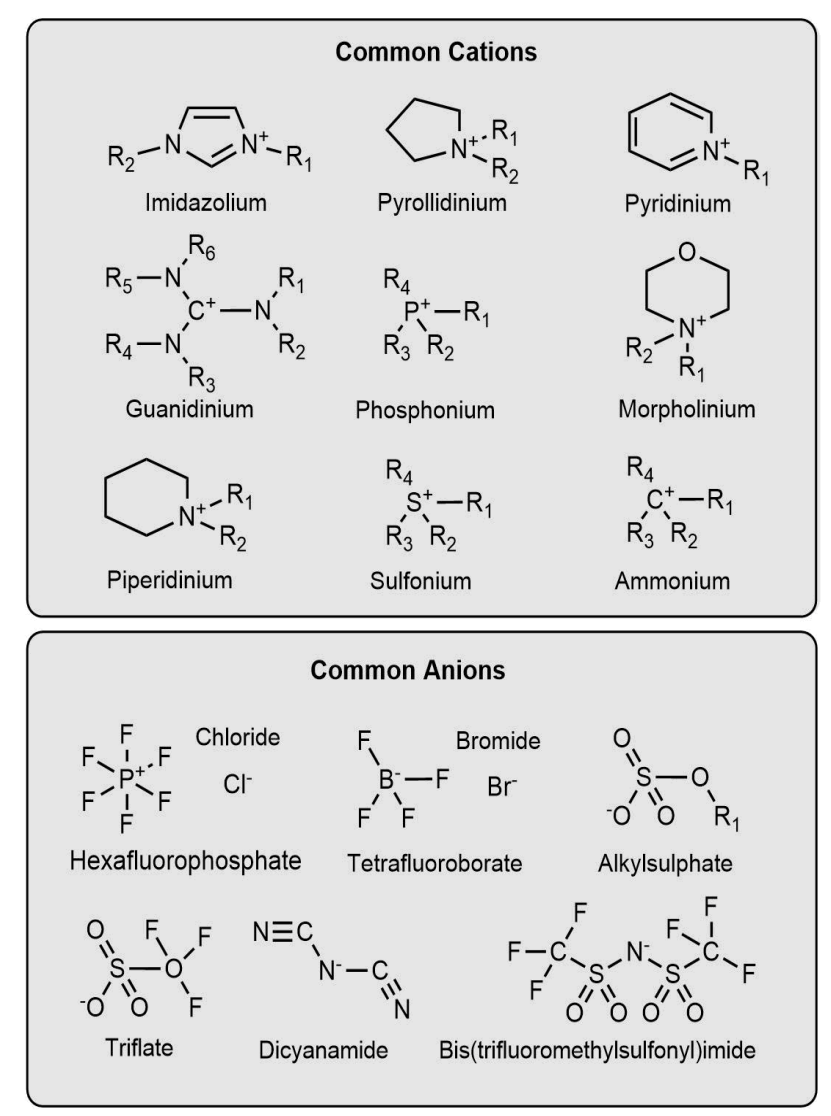

Figure 1. The cations and anions representing the common factor group ${ }^{22}$

\section{Structure of ionic liquids}

The molecular structure of ionic liquids consists of different cations and anions. The cation is usually played by a large organic compound (with a positive charge), but the anions are much smaller in volume than the cations (with a negative charge) and their structure is inorganic. Due to the difference in size between anions and cations, the bond between the two components of ionic liquids is weak, and these compounds are liquid at temperatures below $100^{\circ} \mathrm{C}$. The structure of ionic liquid is similar to that of salt, but due to the strong bond between the cation and its anion (high similarity between anion and cation in terms of size, load, and nature), the salt structure has a strong crystalline structure and melts at $800^{\circ} \mathrm{C}$. Temperatures of $100^{\circ} \mathrm{C}$ are considered for ionic liquids. Those that are liquid at temperatures above $100^{\circ} \mathrm{C}$ are called molten liquids, and those that are liquid below this temperature are called ionic liquids. Some ionic liquids are liquid at room temperature, called RTILs (Room temperature ionic liquids). ${ }^{22}$

The two major groups of ionic liquids are compounds composed of the organic molecules imidazole (cation of the compound imidazole with the formula $\mathrm{C}_{3} \mathrm{H}_{4} \mathrm{~N}_{2}$ ) and pyridinium (the cation of the compound pyridine with the formula $\mathrm{C}_{5} \mathrm{H}_{5} \mathrm{~N}$ ), respectively. The structures of both groups are shown in Figure 2. Various cations and anions are used to make ionic liquids, which can be made using a wide variety of ionic liquids with specific uses or enhanced physical-chemical properties (Tuning of Physicochemical Properties). Common anions include $\mathrm{BF}_{4}^{-}, \mathrm{BF}_{6}^{-}, \mathrm{Br}^{-}, \mathrm{Cl}^{-}$, and so on. 


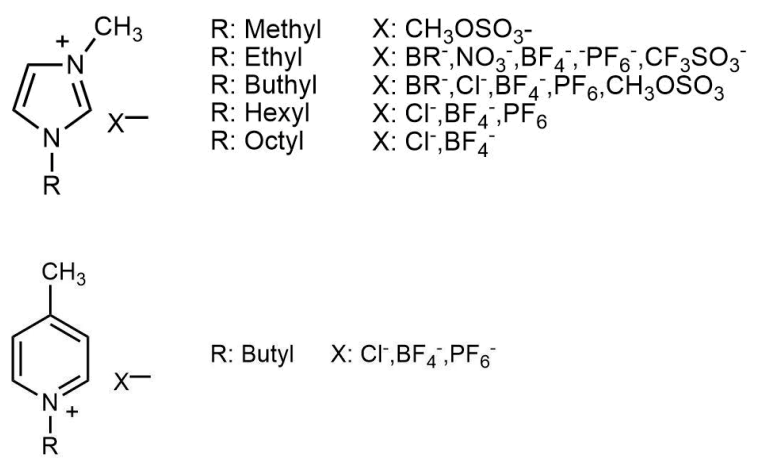

Figure 2. Ionic liquids with cations of imidazole and pyridine ${ }^{22}$

\subsection{Advantages and characteristics of ionic liquids}

The most important advantage of ionic liquids include the following: $:^{22-23}$

They are highly polar.

They have low vapor pressure and are non-volatile.

They are generally stable and resistant to heat up to $300^{\circ} \mathrm{C}$.

They are liquid in a wide range of temperatures, up to $200^{\circ} \mathrm{C}$.

The electrical conductivity of these compounds is very high.

These compounds are incompatible with many common organic solvents.

\section{Properties ionic liquids}

\subsection{Properties of ionic liquids with solvent use}

The presence of volatile and toxic solvents in the chemical industry, which is widely used, is the biggest environmental problem in these industries. An attempt has been made to find a suitable alternative to volatile solvents. The following materials have recently been identified as suitable for this purpose. At the same time, each of the following has its advantages, limitations, and problems. ${ }^{22}$

A) Supercritical $\mathrm{CO}_{2}$

B) Fluorinated solvents

C) Ionic liquids

In the first case, $\mathrm{CO}_{2}$ gas is placed at a temperature and supercritical pressure so that the gas becomes liquid and now has both the properties of gas and liquid. The critical temperature for carbon dioxide gas is $31^{\circ} \mathrm{C}$ and its supercritical pressure is 74 bar. Hyper excitable carbon dioxide is a green solvent but has two major problems. To use this solvent requires the necessary equipment to apply supercritical pressure. Also, the scope of solvency in this solvent is very limited. Fluoride solvents are another group of alternative solvents whose problems are that they are expensive and emit toxic substances due to heat. Ionic liquids are a class of compounds that are now considered the best alternative to volatile solvents. In addition to being green, ionic fluids can dissolve a wide range of organic, inorganic, metalorganic compounds, vital molecules, and metal ions. Due to their ionic structure, these compounds are highly polar and are therefore incompatible with many organic solvents (organic solvents are usually non-polar or have low polarity and are not usually mixed with the aqueous phase). By increasing the length of the alkyl chain attached to the cation, waterinsoluble ionic liquids can be made, and these ionic liquids can be used as organic phases.

\subsection{Purity ionic liquids}

The physical and chemical properties of ionic liquids can change with the presence of impurities. Therefore, the purification of ionic liquids is essential. The most important ionic liquid pollutants are halides or organic and waterbased substrates, which usually come from unreacted materials (precursors of ionic liquid synthesis that remain 
unchanged to the end). Ionic liquids have a strong tendency to absorb moisture, so hydrophobic ionic liquids are also moisture-absorbing. In general, ionic liquids are dried by heating under vacuum, but it is difficult to completely remove water (due to the strong hydrogen bonding). The presence of water reduces the density and viscosity and modulates the chemical properties. $^{22}$

\section{Different generations of ionic liquids}

\subsection{First generation}

Ionic liquids are compounds that are widely used as solvents. These compounds have unique physical properties that can be enhanced by changing their cations or anions. In Figure 3, these ionic liquids are introduced as the first generation.

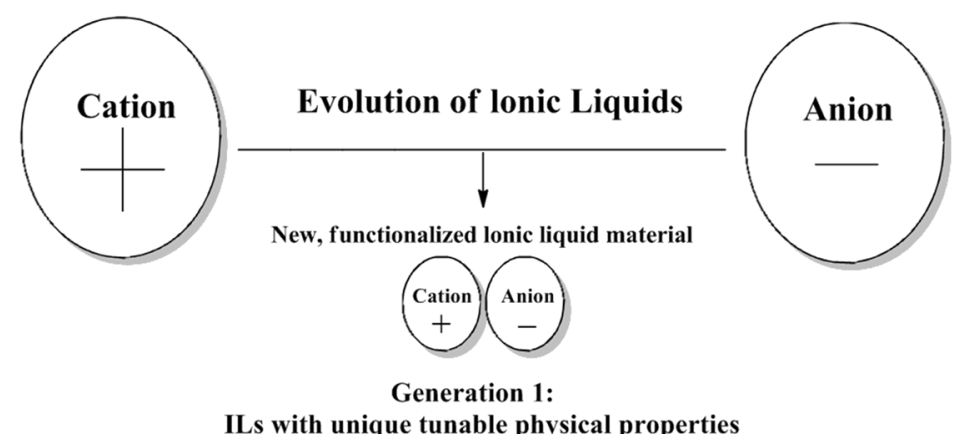

ILs with unique tunable physical properties

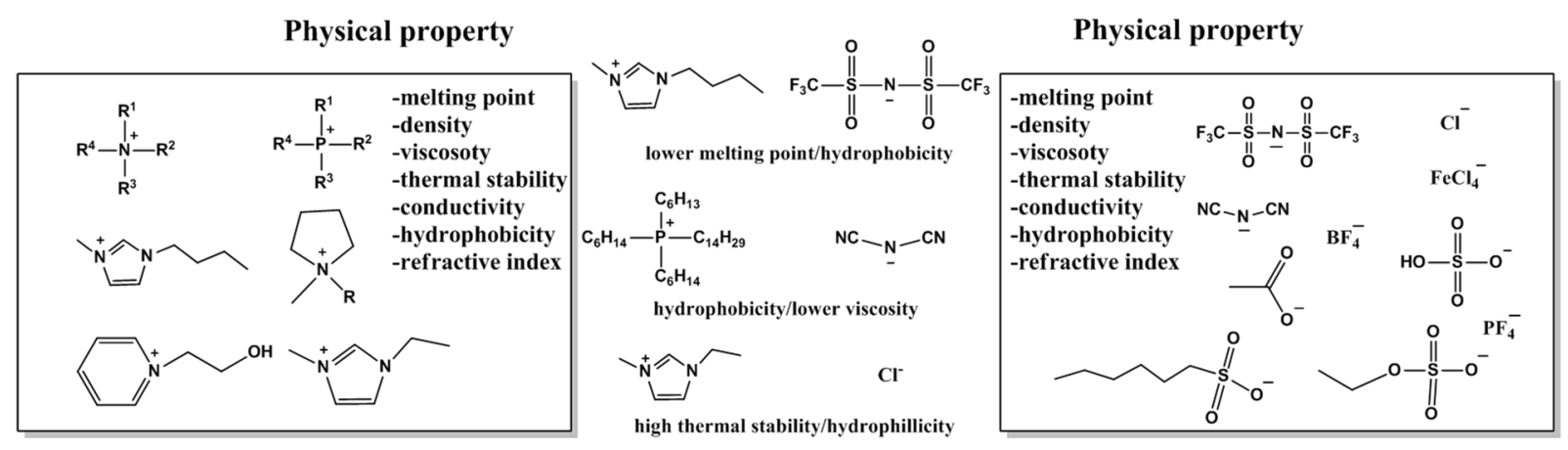

Figure 3. The first generation of ionic liquids with physical, chemical and biological properties ${ }^{22}$

\subsection{Second generation}

With the increasing growth of these compounds, a group of ionic liquids was designed, which are known as ionic liquids with specific chemical use. These compounds have one or more specific functional groups on the cation that can interact and play a specific chemical role. For example, they are used as lubricants and complex ligands. In addition to the physical properties mentioned, these compounds also have chemical efficiencies, known as the second generation of ionic liquids. In Figure 4, these ionic liquids are introduced as the second generation. ${ }^{22}$ 
Generation 2:

ILs with targeted chemical properties combined with chosen physical properties

Chemcial property

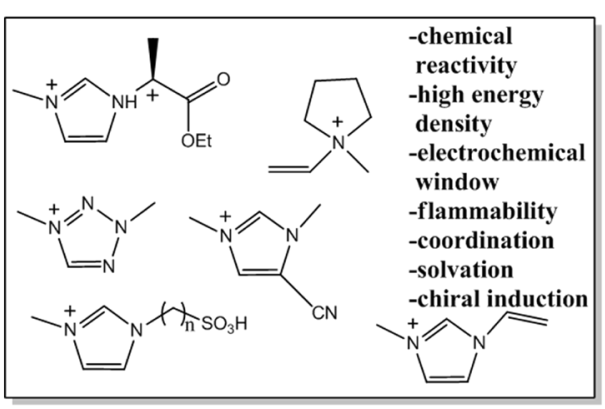

Chemical property

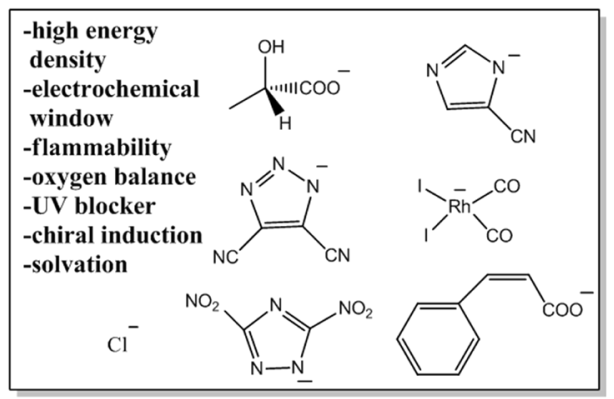

Figure 4. The second generation of ionic liquids with physical, chemical and biological properties

\subsection{Third generation}

Some active pharmaceutical compounds have a structure such as our structure that has classical ionic units and are biologically active and their toxicity has been investigated. Using these drugs, the new generation of ionic liquids of the third generation has been introduced. These compounds have very low toxicity and also have the physical properties of ionic liquids. This means that our ionic ions can be used as drugs. In Figure 5, these ionic liquids are introduced as the third generation.

Generation 3:

ILs with targeted biological properties combined with chosen physical and chemical properties

Biological property

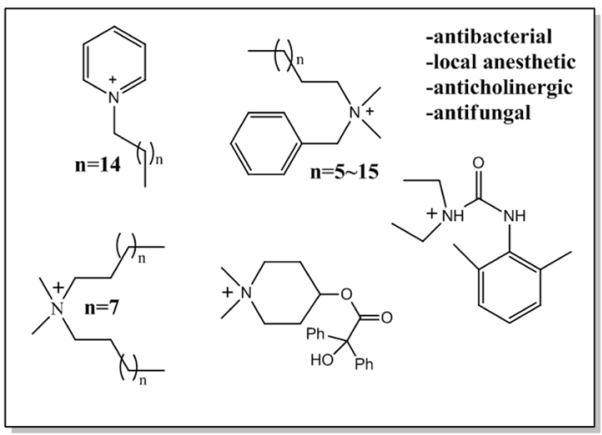

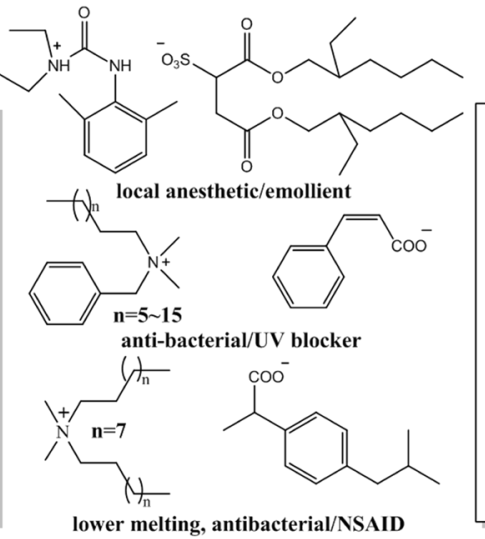

lower melting, antibacterial/NSAID

\section{Biological property}

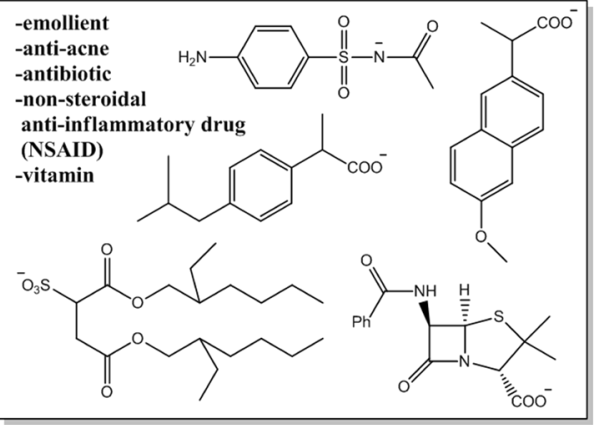

Figure 5. The third generation of ionic liquids with physical, chemical and biological properties

\section{Applications of ionic liquids}

Today, ionic liquids are widely used in various sciences and technologies. The most important use of ionic liquids is to act as a green solvent instead of volatile solvents. Today, ionic liquids have a wide range of other uses, some of which are briefly mentioned. ${ }^{22}$

\subsection{Catalytic reactions}

Ion fluids were first used as a catalyst 20 years ago in the Friedel-Crafts reaction. Ionic liquids are used as a two- 
phase catalyst or substrate to stabilize other catalysts. In the presence of ionic liquids, it is possible to reuse the catalyst. The general state of this reaction is shown in Figure 6.

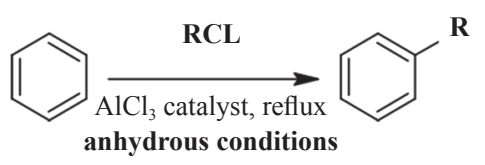

Figure 6. Friedel-Crafts reaction

\subsection{Stability of nanocatalysts in an ionic liquid medium}

Metal nanocatalysts such as gold, platinum, palladium, rhodium, and ruthenium are widely used in organic reactions. The problem with nanocatalysts is that they bind together in reaction environments and become clumpy, greatly reducing their activity. A variety of ionic liquids are used to prevent this. Nanocatalyst Rhodium (Rh) for example, are more active in the ionic liquids mentioned in the hydrogenation reaction of alkenes and rains. ${ }^{22}$

\subsection{Solvent}

As mentioned, the main use of UV fluids is as a solvent. One of the most important benefits of using ionic liquids is increasing the speed of reactions and improving orientation relative to other solvents.

\subsection{Electrochemistry}

More than 20 years ago, molten salts and ionic fluids were first used by electrochemists in power systems. Some ionic fluids were the best examples for electrochemical devices such as power storage, fuel cells, photovoltaic cells, and electric hydration. This is due to the very high electrochemical stability, high conductivity, and wide temperature performance range. The need for high-power batteries for various applications (portable electronics, electric thermopile, mobile phone, etc.) led to the search for more non-aqueous electrolytic solutions. The competition for rechargeable lithium-ion batteries has led to the introduction of high-conductivity electrolytes that are electrochemically stable and have a high capacity for reuse. The ionic liquid appears to be good electrolytes for rechargeable lithium batteries. Their wide range of electrochemical potential prevents the electrode from regenerating or oxidizing. This range is more than 4.5 volts for ionic liquids and 1.2 volts for blue electrolytes. Also, ionic liquids have higher thermal stability, higher conductivity, and higher solubility than conventional electrolytes. For example, their conductivity in lithium batteries is 5 times higher than in mixed and lithium salts in non-aqueous solvents. ${ }^{22}$

\subsection{Liquid-liquid extraction}

One of the methods used for separation is liquid-liquid extraction. This method is widely used in industry because it is very energy efficient. In this method, two non-mixed phases, ie organic and blue phases, are used. Most of the solvents used for the organic phase of chloroform are volatile solvents. Aqueous ionic liquids are a good alternative to the organic phase. Ionic liquids are mainly used in the extraction of valuable metal ions such as gold, lanthanides, and actinides or toxic metal ions of drinking water such as mercury and cadmium. Table 1 lists the ionic liquids used in the metal ion extraction process. 
Table 1. Different ionic liquids with the solvent used in the process of metal ion extraction ${ }^{22}$

\begin{tabular}{cccc}
\hline & Substances & $\mathrm{IL}$ & Extractant/ligand/metal chelator \\
\hline Alkali metals & $\mathrm{Li}^{+}, \mathrm{Na}^{+}, \mathrm{K}^{+}, \mathrm{Rb}^{+}, \mathrm{Cs}^{+}$ & {$[\mathrm{CnMIM}][\mathrm{PF} 6](\mathrm{n}=4-9)$} & $\mathrm{DC}_{18} \mathrm{C}_{6}$ \\
Alkaline earth metals & $\mathrm{Mg}^{2+}, \mathrm{Ca}^{2+}, \mathrm{Sr}^{2+}, \mathrm{Ba}^{2+}$ & {$[$ CnMIM] $][\mathrm{PF} 6](\mathrm{n}=4-9)$} & $\mathrm{DC}_{18} \mathrm{C}_{6}$ \\
Heavy and radioactive metals & $\mathrm{Pb}^{2+}$ & {$[$ CnMIM] $][\mathrm{PF} 6](\mathrm{n}=4-9)$} & $\mathrm{DC}_{18} \mathrm{C}_{6}$ \\
\hline
\end{tabular}

\section{Methods for the synthesis of ionic liquids}

\subsection{Alkylation}

Alkyl cation in many ammoniums, imidazole, pyridinium, and phosphonium-based ionic liquids is obtained by using a suitable precursor (a nucleophile) with the help of an alkylating agent such as haloalkane or a d-alkyl sulk. For example, alkyl imidazole, which are the basic building blocks of imidazole-based ionic liquids, are easily prepared by alkalizing imidazole. Similarly, halogens of alkanes are used to alkaline pyridine and to produce alkyl salts of pyrimidine. Halides Asymmetric, e.g. phosphorus tetrachloride asymmetric are usually produced by increasing the nucleus friendship of the third type of phosphine to halo alkanes. ${ }^{20-23}$

\subsection{Anion exchange}

Many of the ionic liquids used in conventional studies, such as the tetrafluoroborate and hexafluorophosphate ionic liquids, are made in a two-step process with imidazole diacetyl cations. First, the halide salt is prepared by reacting the alkyl with the desired cation. The anion halide is then moved by double replacement with the desired anion. In this process, an anion of an elemental salt is replaced by a mineral anion, such as metal salt group or silver salt. ${ }^{19-20}$

\subsection{Solvent-free synthesis}

The synthesis of non-alcoholic ionic liquids mainly involves two steps:

The use of a haloalkane as an alkylating agent and then the production of unwanted halide salts during the process of double anion exchange. It should be noted that haloalkanes, especially those with high boiling points, are difficult to separate from the product at the end of the reaction. Also, halide salts, which are produced in a double substitution reaction, have a significant effect on the physical properties of ionic liquids. Halide salt impurities may cause poisoning or inactivation of catalysts in which ionic liquid is the solvent of the accelerated reaction with the help of intermediate metals. $^{22}$

\subsection{Synthesis of chiral}

Crystal ionic fluids as a catalyst and solvent are particularly important in asymmetric synthesis. These compounds are derived from chiral sources, which include a wide range of pre-crystal precursors, including synthetic enantiomers (produced on an industrial scale) and amino acids, sugars, terpenes, and other chiral compounds that are naturally derived from plants and animals are obtained. These ionic liquids are usually obtained by alkalizing a pre-crystal precursor and then by the anionic exchange. ${ }^{22}$

\subsection{Synthesis of ionic liquids with a special performance}

The range of applications of ionic liquids contains large-scale cations or anions. Functional ionic liquids, or in other words, ionic liquids with special performance are used as useful solvents in chemical synthesis, catalysts, and materials such as lubricants, missile propulsion, and pharmaceutically active substances. Therefore, there is a growing trend in research into the manufacture of these materials. Various methods have been reported for the preparation of ionic liquids with a special performance. Commonly acting halo alkane is used to make ionic fluids with the causative agents of imidazolium, phosphonium, and pyridinium. One of the first reports on the development of immunosuppressive ionic liquids focused on the extraction of metal ions from aqueous solutions. It is possible to prepare different ionic liquids 
with an ionized agent due to anionic exchange with alkaline salts and commercial acids. ${ }^{22}$

There are other ways to sterilize anion, such as interested fiction. This method has been proposed for the construction of ionic liquids with a functionalized alkyl sulfates anion.

\section{Conclusion}

Ionic liquids are compounds that have revolutionized research centers and chemical industries in recent years. These compounds, these compounds, which are part of green chemistry as a catalyst. Solvent, play a very important role in reducing the use of hazardous, toxic, and environmentally harmful compounds in the pharmaceutical industry. This article briefly describes the benefits and properties of ionic liquids, as well as the applications of these compounds. Today, ionic liquids are widely used in various sciences and technologies. The most important use of ionic liquids is to act as a green solvent instead of volatile solvents.

\section{Acknowledgement}

The authors gratefully thank the Department of Chemical Engineering, Arak Branch, Islamic Azad University, Arak, Iran.

\section{Reference}

[1] Welton, T. Room-temperature ionic liquids: Solvents for synthesis and catalysis. Chem. Rev. 1999, 99, 2071-2084.

[2] Short, P. L. Out of the ivory tower. Chem. Eng. News 2006, 84, 15-21.

[3] Sugden, S.; Wilkins, H. The parachor and chemical constitution. Part XII. Fused metals and salts. J. Chem. Soc. 1929, 1291-1298.

[4] Gorman, J. Faster, better, cleaner?: New liquids take aim at old-fashioned chemistry. Sci. News 2001, 160, 156-158.

[5] Wilkes, J. S. J.; Levisky, A.; Wilson, R. A.; Hussey, C. L. Dialkylimidazolium chloroaluminate melts, a new class of room-temperature ionic liquids for electrochemistry, spectroscopy and synthesis. Inorg. Chem. 1982, 21, 12631264.

[6] Fannin, A. A.; Floreani, D. A.; King, L. A.; Landers, J. S.; Piersma, B. J.; Stech, D. J.; Vaughn, R. L.; Wilkes, J. S.; Williams, J. L. Properties of 1,3-dialkylimidazolium chloride aluminium chloride ionic liquids. Part 2. J. Phys. Chem. 1984, 88, 2614-2627.

[7] Dupont, J. On the solid, liquid and solution structural organization of imidazolium ionic liquids. J. Braz. Chem. Soc. 2004, 15, 341-350.

[8] Brennecke, J. F.; Maginn, E. J. Ionic liquids: Innovative fluids for chemical processing. AIChE J. 2001, 47, 23842388.

[9] Renner, R. Ionic liquids: An industrial cleanup solution. Environ. Sci. Technol. 2001, 35, 410A-413A.

[10 Yang, Q. Dionysiou, D. D. Photolytic degradation of chlorinated phenols in room temperature ionic liquids. $J$. Photochem. Photobiol. A: Chem. 2004, 165, 229-240.

[11] Seddon, R. Room-temperature ionic liquids: Neoteric solvents for clean catalysis. Kinet. Catal. 1996, 37, 693-697.

[12] Lagrost, C.; Carrieř, D.; Vaultier, M.; Hapiot, P. Reactivities of some electrogenerated organic cation radicals in room-temperature ionic liquids: Toward an alternative to volatile organic solvents? J. Phys. Chem. A 2003, 107, 745-752.

[13] Shariati, A.; Peters, C. J. High pressure phase equilibria of systems with ionic liquids. J. Supercrit. Fluids 2005, 34, 171-176.

[14] Shariati, A.; Gutkowski, K.; Peters, C. J. Comparison of the phase behavior of some selected binary systems with ionic liquids. AIChE J. 2005, 51, 1532-1540.

[15] Zhao, H.; Xia, S, Ma, P. Review: Use of ionic liquids as green solvents for extractions, J. Chem. Technol. Biotechnol. 2005, 80, 1089-1096.

[16] Kabo, G. J.; Blokhin, A. V.; Paulechka, A.; Ya, U.; Kabo, A. G.; Shymanovich, M. P.; Magee, J. V. Thermodynamic properties of 1-butyl-3-methylimidazolium hexafluorophosphate in the condensed state. J. Chem. Eng. Data 2004, 49, 453-461. 
[17] Huddleston, J. G.; Willauer, H. D.; Swatloski, R. P.; Visser, A. E.; Rogers, R. D. Room temperature ionic liquids as novel media for clean liquid-liquid extraction. Chem. Commun. 1998, 1765-1766.

[18] Chiappe, C.; Pieraccini, D. Review commentary; ionic liquids: Solvent properties and organic reactivity. J. Phys. Org. Chem. 2005, 18, 275-297.

[19] Donata, D. C.; Marida, F.; Migen, H. University of Torino. http://lem. ch.unito.it/didattica/infochimica/Liquidi\%20 Ionici/Definition.html (accessed June 20, 2006).

[20] Earle, M. J.; Esperanc, J. M. S. S.; Gilea, M. A.; Lopes, J. N. C.; Rebelo, L. P. N.; Magee, J. W.; Seddon, K. R.; Widegren, J. A. The distillation and volatility of ionic liquids. Nature 2006, 72, 1391-1398.

[21] Dupont, J.; Consorti, C. S.; Spencer, J. Room-temperature molten salts: Neoteric green solvents for chemical reactions and processes. J. Braz. Chem. Soc. 2000, 11, 337-344.

[22] Mutelet, F.; Butet, F.; Jaubert, J. N. Application of inverse gas chromatography and regular solution theory for characterization of ionic liquids. Ind. Eng. Chem. Res. 2005, 44, 4120-4127.

[23] Kolle, P.; Dronskowski, R. Synthesis, crystal structures and electrical conductivities of the ionic liquid compounds butyl dimethylimidazolium tetrafluoroborate, hexafluoroborate and hexafluoroantimonate. Eur. J. Inorg. Chem. 2004, 2313-2320.

[24] Carmichael, A. J.; Seddon, K. R. Polarity study of some 1-alkyl-3-methylimidazolium ambient-temperature ionic liquids with the solvatochromic dye, Nile Red. J. Phys. Org. Chem. 2000, 13, 591-595.

[25] Aki, S. N. V. K.; Brennecke, J. F.; Samanta, A. How polar are room temperature ionic liquids? Chem. Commun. 2001, 413-414.

[26] Sheldon, R. A.; Lau, R. M.; Sorgedrager, F.; van Rantwijk, K.; Seddon, R. Biocatalysis in ionic liquids. Green Chem. 2002, 4, 147-151.

[27] Jastorff, B.; Stormann, R.; Ranke, J,; Olter, K. M.; Stock, F.; Oberheitmann, B.; Hoffmann, W.; Hoffmann, J.; Nuchter, M.; Ondruschka, B.; Filser, J. How sustainable are ionic liquids? Structure-activity relationships and biological testing as important elements for sustainability evaluation. Green Chem. 2003, 5, 136-142.

[28] MacFarlane, D. R. Ionic liquids symposium. Aust. J. Chem. 2004, 57, 111-112.

[29] Wilkes, J. S. Properties of ionic liquid solvents for catalysis. Mol. Catal. A. Chem. 2004, 214, 11-17.

[30] Merck Chemicals. http://pb.merck.de/servlet/PB/menu/1341610/index.html (accessed June 26, 2006).

[31] Cammarata, L.; Kazarian, S. G.; Salter, P. A.; Welton, T. Molecular states of water in room temperature ionic liquids. Phys. Chem. Chem. Phys. 2001, 23, 5192-5200.

[32] Hodges, H. C.; Sterner, J. H. Handbook of Toxicilogy: Combined tabulation of toxicity classes, Spector W. S., Ed.; Philadelphia: Saunders Company, 1956.

[33] Maginn, E. J. Research: Ionic Liquids. http://www.nd.edu/ ed/Research/ IL toxicology.html (accessed April 19, 2007).

[34] Wells, A. S.; Coombe, V. T. On the freshwater ecotoxicity and biodegradation properties of some common ionic liquids. Org. Process Res. Dev. 2006, 10, 794-798.

[35] Swatloski, R. P.; Holbrey, J. D.; Memon, S. B.; Caldwell, G. A.; Caldwell, K. A.; Rogers, R. D. Using Caenorhabditis elegans to probe toxicity of 1-alkyl-3-methylimidazolium chloride based ionic liquids. Chem. Commun. 2004, 668-669.

[36] Tran, C. D.; Lacerda, S. H. D. P.; Oliveira, D. Absorption of water by room temperature ILs: Effect of anions on concentration and state of water. Soc. Appl. Spectrosc. 2003, 57, 152-157.

[37] Huddleston, J. G.; Visser, A. E.; Reichert, W. M.; Willauer, H. D.; Broker, G. A.; Rogers, R. D. Characterization and comparison of hydrophilic and hydrophobic room temperature ionic liquids incorporating the imidazolium cation. Green Chem. 2001, 3, 156-164.

[38] Donata, D. C.; Marida, F.; Migen. H.; University of Torino. http://lem.ch. unito.it/didattica/infochimica/Liquidi\%20 Ionici/Composition.html (accessed June 20, 2006).

[39] Ramdin, M.; de Loos, T. W.; Thijs, Vlugt, T. J. H. State-of-the-Art of $\mathrm{CO}_{2}$ Capture with Ionic Liquids. Ind. Eng. Chem. Res. 2012, 51, 8149-8177.

[40] Aki, S. N. V. K.; Mellein, B. R.; Saurer, E. M.; Brennecke, J. F. High-pressure phase behavior of carbon dioxide with imidazolium-based ionic liquids. J. Phys. Chem. B. 2004, 108, 20355-20365.

[41] Kianfar, E.; Shirshahi, M.; Kianfar, F. Simultaneous prediction of the density, viscosity and electrical conductivity of pyridinium-based hydrophobic ionic liquids using artificial neural network. Silicon 2018, 10, 2617-2625.

[42] Vekariya, R. L. A review of ionic liquids: Applications towards catalytic organic transformations. Journal of Molecular Liquids 2017, 227, 44-60.

[43] Friedel, C.; Crafts, J. M. Sur une nouvelle méthode générale de synthèse d'hydrocarbures, d'acétones, etc. Compt. Rend. 1877, 84, 1395-1450.

[44] Zhao. H.; Xia, S.; Ma, P. Use of ionic liquids as 'green' solvents for extractions. Journal of Chemical Technology 
and Biotechnology. 2005, 80, 1089.

[45] Liu, H.; Kianfar, E. Investigation the synthesis of nano-SAPO-34 catalyst prepared by different templates for MTO process. Catal Lett. 2020. https://doi.org/10.1007/s10562-02.

[46] Yang, Z.; Zhang, L.; Zhou, Y.; Wang, H.; Wen, L.; Kianfar, E. Investigation of effective parameters on SAPO-34 nanocatalyst in the methanol-to-olefin conversion process: A review. Reviews in Inorganic Chemistry, 2020, https:// doi.org/10.1515/revic-2020-0003.

[47] Kianfar, E.; Salimi, M. A review on the production of light olefins from hydrocarbons cracking and methanol conversion. Advances in Chemistry Research 2020, 59, 1-81.

[48] Kianfar, E.; Razavi, A. Zeolite catalyst based selective for the process MTG: Zeolites: Advances in research and applications, Mahler A. Ed.; Chapter: 8; NY, USA: Nova Science Publishers, Inc., 2020. 